\title{
Prevalence and Complications of Pregestational and Gestational Diabetes in Saudi Women: Analysis from Riyadh Mother and Baby Cohort Study (RAHMA)
}

\author{
Hayfaa Wahabi, ${ }^{1,2}$ Amel Fayed, ${ }^{3,4}$ Samia Esmaeil, ${ }^{1}$ Heba Mamdouh, ${ }^{5}$ and Reham Kotb ${ }^{6}$ \\ ${ }^{1}$ Chair for Evidence-Based Health Care and Knowledge Translation, College of Medicine, King Saud University, Riyadh, Saudi Arabia \\ ${ }^{2}$ Department of Community and Family Medicine, King Saud University, Riyadh, Saudi Arabia \\ ${ }^{3}$ Department of Biostatistics, High Institute of Public Health, Alexandria University, Alexandria, Egypt \\ ${ }^{4}$ College of Medicine, Princess Nourah Bint Abdulrahman University, Riyadh, Saudi Arabia \\ ${ }^{5}$ Department of Family Health, High Institute of Public Health, Alexandria University, Alexandria, Egypt \\ ${ }^{6}$ Department of Primary Health Care, High Institute of Public Health, Alexandria University, Alexandria, Egypt
}

Correspondence should be addressed to Hayfaa Wahabi; umlena@yahoo.com

Received 28 December 2016; Accepted 14 February 2017; Published 12 March 2017

Academic Editor: Yoshifumi Saisho

Copyright (C) 2017 Hayfaa Wahabi et al. This is an open access article distributed under the Creative Commons Attribution License, which permits unrestricted use, distribution, and reproduction in any medium, provided the original work is properly cited.

The objectives of this study were to estimate the burden of diabetes and to explore the adverse pregnancy outcomes associated with pregestational diabetes mellitus (pre-GDM) and gestational diabetes mellitus (GDM) among the Saudi pregnant population. In this subcohort, we compared the maternal and the neonatal outcomes of diabetic women with pre-GDM and GDM to the outcomes of nondiabetic mothers who delivered during the same period. From the total cohort, 9723 women participated in this study. Of the participants, $24.2 \%$ had GDM, $4.3 \%$ had pre-GDM, and 6951 were nondiabetic. After adjustment for confounders, women with GDM had increased odds of delivering a macrosomic baby (OR: 1.6; 95\% CI: 1.2-2.1). Women with pre-GDM were more likely to deliver by Cesarean section (OR: 1.65; CI: 1.32-2.07) and to have preterm delivery < 37 weeks (OR: 2.1; CI: 1.5-2.8). Neonates of mothers with pre-GDM were at increased risk of being stillbirth (OR: 3.66; CI: 1.98-6.72), at increased risk of admission to NICU (OR: 2.21; CI: 1.5-3.27), and at increased risk for being macrosomic (OR: 2.40; CI: 1.50-3.8). The prevalence of GDM and pre-GDM in the Saudi pregnant population is among the highest in the world. The conditions are associated with high maternal and neonatal morbidities and mortalities.

\section{Introduction}

According to the International Diabetes Federation (IDF), the epidemiology of diabetes during pregnancy is unknown in many countries in the world [1]. Nevertheless, more than 21 million pregnancies were affected by diabetes during the year 2013 [1]. Saudi Arabia is among the top ten countries in the world with the highest prevalence of diabetes $[1,2]$. A recent report from Saudi Arabia estimated the prevalence of pregestational diabetes mellitus (Pre-GDM) and gestational diabetes mellitus (GDM) in Riyadh, the capital city of Saudi Arabia, to be $4.3 \%$ and $24.3 \%$, respectively [3]. This prevalence reflects high burden of diabetes among pregnant women compared to other populations in the world $[4,5]$.
Pregnancies complicated by maternal diabetes are associated with adverse maternal and neonatal outcomes including increased rate of Cesarean section delivery, macrosomia, admission to neonatal intensive care unit (NICU), and perinatal mortality $[6,7]$. Interventions such as preconception care for women with pre-GDM and screening and control of hyperglycemia during pregnancy for women with GDM have been proven to improve the outcomes for pregnancies complicated with diabetes [8-10]. Hence, it is important to estimate the burden of diabetes and its complication among pregnant women to direct health resource to improve the outcomes for these high-risk pregnancies.

We used data from a subcohort of RAHMA study to estimate the burden of diabetes among pregnant women and 
to explore the adverse pregnancy outcomes associated with pre-GDM and GDM in Saudi pregnant population.

\section{Methods}

2.1. Study Setting. RAHMA is the first large multicenter cohort study which investigates pregnancy outcomes in Saudi Arabia. Because RAHMA has systematically recruited a large number of pregnant women, it is expected to provide accurate estimate of the indices of maternal morbidity in Riyadh and to a great extent in Saudi Arabia generally, bearing in mind that more than $25 \%$ of the Kingdom's population (7.3 million) lives in Riyadh [11] and that all women deliver in hospitals. The participating hospitals were selected randomly after stratification based on the type of hospital (ministry of health, military, or teaching) and the number of beds which ensured that the participants in the study were representatives of all the spectra of pregnant women in Riyadh. The detailed methodology of the study has been previously reported [3].

The main objectives of the study were to examine the influence of noncommunicable diseases including diabetes, hypertension, and obesity as well as the effect of the socioeconomic factors such as urbanization, education, and smoking on the outcomes of pregnancy. RAHMA recruited 14,568 women during the period from 2013 to 2015. Participants completed a self-administered questionnaire providing information on family socioeconomic and lifestyle status and antenatal history. In addition, maternal and neonatal outcomes were reported. A link was established between maternal laboratory data and the study records [3].

2.2. Study Population. In this subcohort, we compared the maternal and the neonatal outcomes of diabetic women with pre-GDM (type 1 and type 2) and GDM to the outcomes of nondiabetic mothers who delivered during the same period. In addition, we compared the outcomes of pregnancies complicated with type 1 diabetes mellitus (T1DM) to those complicated with type 2 diabetes mellitus (T2DM).

Due to the variable cut-off values for the diagnosis of GDM and pre-GDM in the three participating hospitals, we collected the results of the OGTT between 24 and 34 gestation weeks and the fasting blood glucose $\leq 14$ weeks of gestation to reclassify the participants as nondiabetic, pre-GDM, or GDM based on the following World Health Organization (WHO) cut-off values [12]:

Gestational diabetes mellitus should be diagnosed at any time in pregnancy if one or more of the following criteria are met:

(i) Fasting plasma glucose 5.1-6.9 mmol/1 (92$125 \mathrm{mg} / \mathrm{dl}$ ).

(ii) 1-Hour plasma glucose $\geq 10.0 \mathrm{mmol} / \mathrm{l}$ (180 mg/ dl) following a $75 \mathrm{~g}$ oral glucose load.

(iii) 2-Hour plasma glucose $8.5-11.0 \mathrm{mmol} / 1$ (153$199 \mathrm{mg} / \mathrm{dl}$ ) following a $75 \mathrm{~g}$ oral glucose load.

Diabetes in pregnancy should be diagnosed if one or more of the following criteria are met: (i) Fasting plasma glucose $\geq 7.0 \mathrm{mmol} / 1$ (126 mg/ dl).

(ii) 2-Hour plasma glucose $\geq 11.1 \mathrm{mmol} / 1$ (200 mg/ dl) following a $75 \mathrm{~g}$ oral glucose load.

(iii) Random plasma glucose $\geq 11.1 \mathrm{mmol} / \mathrm{l}$ (200 mg/ $\mathrm{dl})$ in the presence of diabetes symptoms.

Maternal prepregnancy body mass index (BMI) was calculated from maternal recall of weight prior to pregnancy and the height measured during the first antenatal clinic and then the participants were classified according to the WHO weight classification. The following BMI definitions were used in this study: underweight $\left(<18.5 \mathrm{~kg} / \mathrm{m}^{2}\right)$, normal $\left(18.5-24.9 \mathrm{~kg} / \mathrm{m}^{2}\right)$, overweight $\left(25.0-29.9 \mathrm{~kg} / \mathrm{m}^{2}\right)$, and obese $\left(\geq 30 \mathrm{~kg} / \mathrm{m}^{2}\right)[13]$.

For the purpose of this study, preeclampsia was defined as new onset of elevated blood pressure after 20 weeks of pregnancy in a previously normotensive woman $(\geq 140 \mathrm{mmHg}$ systolic or $\geq 90 \mathrm{mmHg}$ diastolic on at least two occasions $6 \mathrm{~h}$ apart) in addition to proteinuria of at least $1+$ on a urine dipstick or $\geq 300 \mathrm{mg}$ in a 24-hour urine collection. Eclampsia is defined as seizures in a preeclamptic woman that cannot be attributed to other causes. Gestational hypertension is defined as new onset of elevated blood pressure $(\geq 140 \mathrm{mmHg}$ systolic or $\geq 90 \mathrm{mmHg}$ diastolic on at least two occasions $6 \mathrm{~h}$ apart) after 20 weeks of gestation in a previously normotensive woman and superimposed preeclampsia is defined as new onset of preeclampsia after 20 weeks of pregnancy in a previously hypertensive woman [14].

The inclusion criteria for this subcohort were the following:

(1) Gestational age of 24 weeks or more at the time of delivery, calculated from the last menstrual period and/or early ultrasound scan

(2) Singleton pregnancy

(3) Women diagnosed with either T1DM or T2DM before the index pregnancy or according to the WHO criteria during index pregnancy and women with GDM (study groups)

(4) Women with neither pre-GDM nor GDM (control group)

We excluded women with unknown glycemic status from the analysis.

The demographic characteristics and the pregnancy outcomes of the women with pre-GDM and GDM were compared to the outcomes of nondiabetic women. Women with multiple pregnancies were excluded from the analysis of the outcomes; however, all deliveries more than 24 weeks were considered when calculating the prevalence rate of pre-GDM and GDM.

2.3. Outcomes. The maternal variables we compared were age, parity, induction of labour, mode of delivery, premature delivery, rate of hypertensive disorders in pregnancy, and prepregnancy BMI. The neonatal outcomes included birth weight, macrosomia (birth weight $\geq 4 \mathrm{~kg}$ ), low birth weight, 
shoulder dystocia, APGAR scores at $5 \mathrm{~min}$ after delivery, admission to neonatal intensive care unit (NICU), and the prevalence of stillbirth.

2.4. Statistical Analysis. Data were analyzed using Statistical Package for the Social Sciences (SPSS), Version 20 (SPSS Inc., Chicago, IL, USA). ANOVA test was used to compare means and Chi squire test was used to compare categorical variables between the three groups. Odds Ratio (OR) was calculated and $P$ value of less than 0.05 was considered significant. We used regression analysis to adjust for covariates including maternal age, BMI, and parity. Nondiabetic women were taken as reference group.

2.5. Ethical Approval. The Review Boards of the following institutions reviewed and approved the main cohort study (RAHMA) from which a subgroup population was included in this study: King Abdullah International Medical Research Centre (approval letter: 11/062), King Fahad Medical City Research Centre (approval letter: 013-017), and King Saud University (approval letter: 13-985). The study was conducted according to the principles expressed in the Declaration of Helsinki.

\section{Results}

From the total cohort, 9723 women had OGTT and were included in this study, while 4845 were not screened giving a screening rate of $66.7 \%$. The reasons for the missing OGTT results were as follows: 2695 participants (18.5\%) did not have the test because they either did not book for antenatal care or booked after 34 weeks of gestation, 1530 participants (10.5\%) were screened for GDM during their antenatal care in hospitals other than those participating in the study and the results were not available, and the remaining 582 participants (4\%) declined to have the test for various reasons.

Comparison of the main demographic characteristics and determinants of GDM between women who had OGTT test results and those who did not showed no systematic difference between the two groups (see Appendix).

Of the participants of the study, 2354 (24.2\%) had GDM, 418 (4.3\%) had pre-GDM, and 6951 were nondiabetic. Table 1 shows the comparison between the demographic characteristics of the three groups. There were no significant differences between the three groups in the socioeconomic characteristics. However, women with GDM and pre-GDM were significantly older and of higher parity when compared to nondiabetic women (Table 1). While less than $20 \%$ of women between 20 and 24 years were diabetic, we found that more than $45 \%$ of women with 45 years or more were diabetic (Table 1). In addition, the prevalence of GDM and pre-GDM increases with the increase of maternal age, with slight drop in the prevalence of GDM after 44 years of age (Figure 1). While more than $75 \%$ of women with GDM were between 25 and 39 years, more than $70 \%$ of women with pre-GDM were between 30 and 44 years, which indicates a later onset of pre-GDM compared to GDM (Table 1).

Comparison of the maternal and neonatal outcomes between women with pre-GDM, those with GDM, and nondiabetic women is shown in Table 2 . The pregnancy outcomes

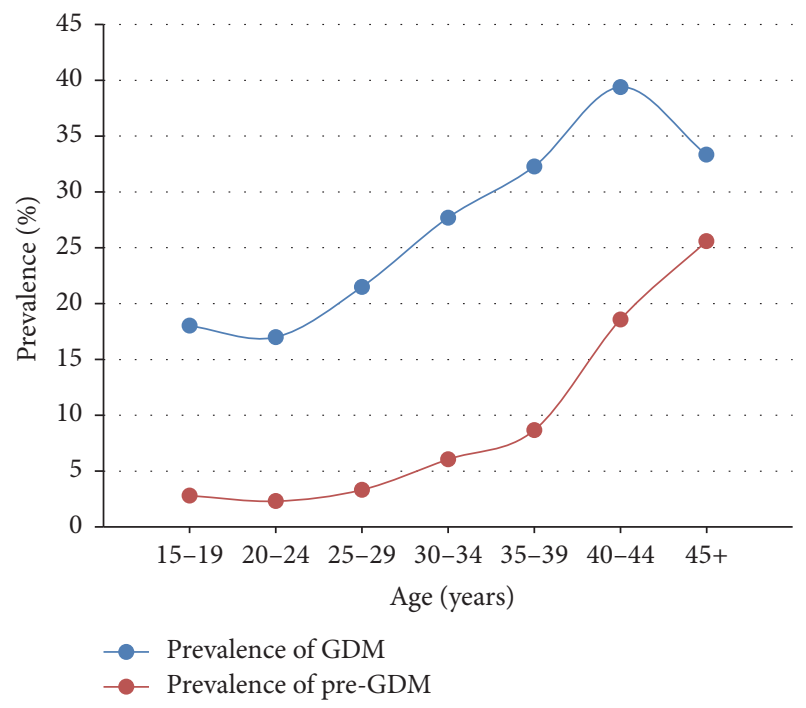

Figure 1: Prevalence of gestational and pregestational diabetes by age range.

for women with GDM were comparable to the outcomes of nondiabetic women except for macrosomia (Table 2). However, women with pre-GDM had significantly increased proportion of adverse pregnancy outcomes compared to nondiabetic women, including preterm delivery between 34 and 36 weeks, stillbirth rate, neonatal admission to intensive care unit (NICU), macrosomia, low APGAR scores, and shoulder dystocia (Table 2). In addition, higher proportion of women with pre-GDM had hypertensive disorders during pregnancy, induction of labour, and Cesarean section delivery (Table 2).

After adjustment for maternal age, parity, and BMI, women with GDM had increased odds of delivering a macrosomic baby (Odds Ratio (OR): 1.6; 95\% confidence interval (CI): 1.2-2.1) compared to nondiabetic women, with no significant increase risk for other maternal or neonatal complications. However, women with pre-GDM continued to have increased risk of developing complication after adjustment. They were more likely to have induction of labour (OR: 1.67; CI: 1.28-2.13), to deliver by Cesarean section (OR: 1.65; CI: 1.32-2.07), and to have preterm delivery < 37 weeks (OR: 2.1; CI: 1.5-2.8) compared to nondiabetic women. Neonates of mothers with pre-GDM were at more than threefold increased risk of being stillbirth (OR: 3.66; CI: 1.98-6.72), at nearly fourfold increased risk of having low APGAR scores at birth (OR: 3.82; CI: 2.26-6.45), at more than twofold increased risk of admission to NICU (OR: 2.21; CI: 1.5-3.27), and at more than twofold increased risk for macrosomia (OR: 2.40; CI: 1.50-3.8), compared to neonates of nondiabetic mothers (Table 3 ).

The relationship between the prevalence of GDM and preGDM and BMI is shown in Figure 2. Both conditions showed increased prevalence with increase in BMI.

The comparison of the maternal characteristics and the neonatal outcomes between women with T1DM and T2DM and the women diagnosed as diabetic during the index pregnancy is shown in Table 4 . Almost $50 \%$ of the women 
TABLE 1: The demographic characteristics of women with pregestational diabetes, those with gestational diabetes, and nondiabetic women.

\begin{tabular}{|c|c|c|c|c|}
\hline Characteristic & $\begin{array}{c}\text { Nondiabetic } \\
\text { Number (\%) } \\
N=6951(71.5)\end{array}$ & $\begin{array}{c}\text { GDM } \\
\text { Number (\%) } \\
N=2354(24.2)\end{array}$ & $\begin{array}{c}\text { Pre-GDM } \\
\text { Number (\%) } \\
N=418(4.3)\end{array}$ & $P$ value \\
\hline Age $($ mean $\pm S D)$ & $29.5 \pm 5.7$ & $31.5 \pm 5.9$ & $33.6 \pm 6.2$ & $<0.001$ \\
\hline \multicolumn{5}{|l|}{ Age range (years) } \\
\hline$<20$ & $173(2.5)$ & $38(1.6)$ & $5(1.2)$ & \\
\hline $20-24$ & $1322(19)$ & $271(11.5)$ & $32(7.7)$ & \\
\hline $25-29$ & $2179(31.3)$ & $596(25.3)$ & $75(17.9)$ & \\
\hline $30-34$ & $1799(25.9)$ & $688(29.2)$ & $116(27.8)$ & \\
\hline $35-39$ & $1126(16.2)$ & $537(22.8)$ & $106(25.4)$ & \\
\hline $40-44$ & $320(4.6)$ & $208(8.8)$ & $73(17.5)$ & \\
\hline $45+$ & $32(0.5)$ & $16(0.7)$ & $11(2.6)$ & \\
\hline \multicolumn{5}{|l|}{ Education } \\
\hline Illiterate & $123(3.0)$ & $40(3.0)$ & $5(2.1)$ & 0.26 \\
\hline School & $2259(54.7)$ & $727(55.3)$ & $145(62.2)$ & \\
\hline University and above & $1747(42.3)$ & $547(41.6)$ & $83(35.6)$ & \\
\hline Missing & 2822 & 1040 & 185 & \\
\hline \multicolumn{5}{|l|}{ Working status } \\
\hline Housewife & $5179(86.5)$ & $1754(86.7)$ & $317(88.8)$ & 0.39 \\
\hline Employed & $765(12.8)$ & $251(12.4)$ & $40(11.2)$ & \\
\hline Student & $46(0.8)$ & $18(0.9)$ & $0(0.0)$ & \\
\hline Missing & 961 & 331 & 61 & \\
\hline \multicolumn{5}{|l|}{ Parity } \\
\hline Nullipara & $1655(23.8)$ & $378(16.1)$ & $64(15.3)$ & $<0.01$ \\
\hline $2-4$ & $3351(48.2)$ & $1090(46.3)$ & $130(31.1)$ & \\
\hline Grand multipara & $1941(27.9)$ & $885(37.6)$ & $224(53.6)$ & \\
\hline Missing & 4 & 1 & 0 & \\
\hline \multicolumn{5}{|c|}{ BMI before pregnancy $\left(\mathrm{kg} / \mathrm{m}^{2}\right)$} \\
\hline Less than 18.5 & $96(2.6)$ & $16(1.3)$ & $0(0.0)$ & $<0.01$ \\
\hline 18.5 to 25 & $1200(32.4)$ & $263(20.8)$ & $38(17.5)$ & \\
\hline 25.1 to $<30$ & $1227(33.1)$ & $351(27.8)$ & $61(28.1)$ & \\
\hline 30 or more & $1179(31.8)$ & $633(50.1)$ & $118(54.4)$ & \\
\hline
\end{tabular}

Data expressed as mean \pm SD or $N(\%)$. BMI: body mass index; GDM: gestational diabetes mellitus; Pre-GDM: preexisting gestational diabetes mellitus.

with pre-GDM in this subcohort were diagnosed during pregnancy. The three groups were similar in most of the maternal characteristics and pregnancy outcomes except for preterm delivery where women with T1DM had significantly more preterm deliveries compared to the other two groups (Table 4).

\section{Discussion}

Our results showed that almost 30\% of the obstetric population in Riyadh suffers from the adverse effects of either pre-GDM or GDM and that nearly $50 \%$ of pregnant women with T2DM were unaware of their condition. In addition, the study demonstrated the increased morbidities and mortalities associated with pre-GDM compared to GDM and between T1DM and T2DM.
The high prevalence of $24 \%$ and $4.3 \%$ for GDM and pre-GDM, respectively, is quite alarming, considering the high risk for adverse pregnancy outcomes associated with diabetes in pregnancy. Although our estimated prevalence is consistent with that detected by global estimates of GDM and pre-GDM in the region and from similar studies in Saudi Arabia [5-7, 15], it is much higher than the prevalence reported from USA and Europe [5]. Such finding is expected due to the established relationship between ethnicity and epidemiology of pre-GDM and GDM [16, 17].

Moreover, such high rate of GDM and pre-GDM is anticipated in Saudi pregnant women, considering the high burden of diabetes in the adult population in the country [18] and the fact that epidemiology of GDM is directly related to that of T2DM in the population [19]. 
TABLE 2: Comparison of the maternal and neonatal outcomes between women with pregestational diabetes, those with gestational diabetes, and nondiabetic women.

\begin{tabular}{|c|c|c|c|c|}
\hline Characteristic & $\begin{array}{c}\text { Nondiabetic } \\
N=6951(71.5)\end{array}$ & $\begin{array}{c}\text { GDM } \\
N=2354(24.2)\end{array}$ & $\begin{array}{c}\text { Pre-GDM } \\
N=418(4.3)\end{array}$ & $P$ value \\
\hline \multicolumn{5}{|l|}{ Pregnancy } \\
\hline Single & $6763(97.3)$ & $2282(96.9)$ & $403(96.4)$ & 0.42 \\
\hline Multiple & $188(2.7)$ & $72(3.1)$ & $15(3.6)$ & \\
\hline \multicolumn{5}{|l|}{ Gestational age (for live births) } \\
\hline 24-34 weeks & $143(2.1)$ & $59(2.5)$ & $11(2.7)$ & $<0.01$ \\
\hline 34-36 weeks & $398(5.8)$ & $137(5.9)$ & $48(11.9)$ & \\
\hline 37-41 weeks & $6190(90.6)$ & $2092(90.3)$ & $341(84.4)$ & \\
\hline More than 41 weeks & $104(1.5)$ & $30(1.3)$ & $4(1.0)$ & \\
\hline Induced labour & $1108(16.0)$ & $420(17.9)$ & $95(22.8)$ & $<0.001$ \\
\hline \multicolumn{5}{|l|}{ Birth weight (full term) } \\
\hline Normal (2.5-3.9 kg) & $5770(91.6)$ & $1906(89.6)$ & $311(88.4)$ & $<0.001$ \\
\hline $\mathrm{LBW}<2.5 \mathrm{~kg}$ & $374(5.9)$ & $118(5.5)$ & $19(5.4)$ & \\
\hline Macrosomia $\geq 4.0 \mathrm{~kg}$ & $156(2.5)$ & $103(4.8)$ & $22(6.2)$ & \\
\hline Stillbirth & $60(0.9)$ & $22(0.9)$ & $12(2.9)$ & $<0.01$ \\
\hline Shoulder dystocia & $26(0.4)$ & $8(0.3)$ & $5(1.2)$ & 0.03 \\
\hline Neonatal admission to NICU & $281(4.1)$ & $110(4.7)$ & $33(8.0)$ & 0.001 \\
\hline APGAR $<7$ (for full term) & $42(0.7)$ & $21(1.0)$ & $11(3.1)$ & $<0.001$ \\
\hline \multicolumn{5}{|l|}{ Hypertension disorder } \\
\hline Preexisting hypertension & $69(1.0)$ & $32(1.4)$ & $18(4.3)$ & $<0.01$ \\
\hline Gestational hypertension & $90(1.3)$ & $43(1.8)$ & $18(4.3)$ & $<0.01$ \\
\hline Preeclampsia/superimposed & $74(1.1)$ & $24(1.0)$ & $9(2.2)$ & 0.12 \\
\hline \multicolumn{5}{|l|}{ Mode of delivery } \\
\hline Vaginal & $4958(71.9)$ & $1585(67.6)$ & $239(57.5)$ & $<0.01$ \\
\hline Instrumental & $284(4.1)$ & $84(3.6)$ & $11(2.6)$ & \\
\hline Cesarean section & $1657(24.0)$ & $675(28.8)$ & $166(39.9)$ & \\
\hline $\begin{array}{l}\text { Structural anomalies } \\
\text { detected by antenatal USS }\end{array}$ & $97(1.4)$ & $35(1.5)$ & $8(1.9)$ & 0.67 \\
\hline
\end{tabular}

Data expressed as $N$ (\%). GDM: gestational diabetes mellitus; Pre-GDM: preexisting gestational diabetes mellitus; NICU: neonatal intensive care unit; LBW: low birth weight; USS: ultrasound scan.

TABLE 3: Crude and adjusted Odds Ratio for maternal and neonatal complications in diabetic women compared to nondiabetic women.

\begin{tabular}{|c|c|c|c|c|}
\hline \multirow{2}{*}{ Outcome } & \multicolumn{2}{|c|}{$\begin{array}{c}\text { GDM } \\
N=2354(24.2)\end{array}$} & \multicolumn{2}{|c|}{$\begin{array}{c}\text { Pre-GDM } \\
N=418(4.3)\end{array}$} \\
\hline & $\begin{array}{c}\text { Crude OR } \\
(95 \% \mathrm{CI})\end{array}$ & $\begin{array}{c}\text { Adjusted OR } \\
(95 \% \mathrm{CI})\end{array}$ & $\begin{array}{c}\text { Crude OR } \\
(95 \% \text { CI })\end{array}$ & $\begin{array}{c}\text { Adjusted OR } \\
(95 \% \text { CI })\end{array}$ \\
\hline Cesarean section & $1.28(1.1-1.4)^{*}$ & $1.05(0.94-1.18)$ & $2.1(1.7-2.5)^{*}$ & $1.65(1.32-2.1)^{*}$ \\
\hline Induction of labour & $1.1(1.01-1.3)^{*}$ & $1.39(1.0-1.3)$ & $1.55(1.2-1.9)^{*}$ & $1.67(1.28-2.1)^{*}$ \\
\hline Preterm delivery < 37 weeks & $1.1(0.9-1.3)$ & $1.0(0.8-1.3)$ & $2.0(1.5-2.7)^{*}$ & $2.1(1.5-2.8)^{*}$ \\
\hline Stillbirth & $1.08(0.66-1.77)$ & $1.1(0.68-1.78)$ & $3.39(1.8-6.3)^{*}$ & $3.66(1.9-6.7)^{*}$ \\
\hline Macrosomia & $2.1(1.6-2.7)^{*}$ & $1.6(1.2-2.1)^{*}$ & $2.7(1.7-4.4)^{*}$ & $1.6(1.1-2.7)^{*}$ \\
\hline Shoulder dystocia & $0.9(0.4-2.0)$ & $1.0(0.41-2.43)$ & $3.2(1.2-8.4)^{*}$ & $2.4(0.7-8.5)$ \\
\hline $\mathrm{APGAR}<7$ at $5 \mathrm{~min}$ & $1.4(0.87-2.5)$ & $1.25(0.84-1.86)$ & $4.4(2.2-8.7)^{*}$ & $3.82(2.26-6.45)^{*}$ \\
\hline Admission to NICU & $1.2(0.96-1.51)$ & $1.16(0.91-1.48)$ & $2.12(1.5-3.1)^{*}$ & $2.21(1.5-3.27)^{*}$ \\
\hline
\end{tabular}

OR: Odds Ratio; GDM: gestational diabetes mellitus; Pre-GDM: preexisting gestational diabetes mellitus; NICU: neonatal intensive care unit. OR is adjusted for maternal age, parity, and BMI. Nondiabetic women are reference group.

${ }^{*} P$ value $<0.05$. 
TABLE 4: Comparison of the maternal characteristics and neonatal outcomes between women with type 1 and type 2 diabetes mellitus.

\begin{tabular}{|c|c|c|c|c|}
\hline Characteristic & $\begin{array}{c}\text { Type } 1 \\
(n=73)\end{array}$ & $\begin{array}{c}\text { Type } 2 \\
(n=141)\end{array}$ & $\begin{array}{c}\text { Diagnosed during } \\
\text { pregnancy } \\
(n=204) \\
\end{array}$ & $P$ value \\
\hline Age & $33.1 \pm 6.3$ & $35.3 \pm 5.7$ & $34.8 \pm 5.0$ & 0.02 \\
\hline BMI & $34.5 \pm 6.0$ & $35.9 \pm 7.4$ & $36.1 \pm 6.5$ & 0.22 \\
\hline Parity & $3.1 \pm 2.7$ & $4.1 \pm 2.7$ & $3.5 \pm 2.6$ & 0.02 \\
\hline Cesarean section delivery & $34(46.6)$ & $79(56.8)$ & $98(48.8)$ & 0.24 \\
\hline \multicolumn{5}{|l|}{ Preterm delivery } \\
\hline 24-33 weeks & $4(5.6)$ & $5(3.5)$ & $7(3.4)$ & 0.74 \\
\hline 34-36 weeks & $19(26.4)$ & $25(17.7)$ & $25(12.3)$ & 0.02 \\
\hline Stillbirth & $3(4.1)$ & $4(2.8)$ & $7(3.4)$ & 0.88 \\
\hline Macrosomia & $4(5.6)$ & $12(8.6)$ & $4(2.0)$ & 0.08 \\
\hline APGAR $<7$ at 5 minutes & $1(1.4)$ & $6(4.3)$ & $9(4.5)$ & 0.49 \\
\hline Shoulder dystocia & $0(0.0)$ & $1(0.7)$ & $4(2.0)$ & 0.59 \\
\hline Admission to NICU & $8(11.0)$ & $15(10.8)$ & $13(6.5)$ & 0.29 \\
\hline
\end{tabular}

Data expressed as mean \pm SD or $N$ (\%). BMI: body mass index; NICU: neonatal intensive care unit.

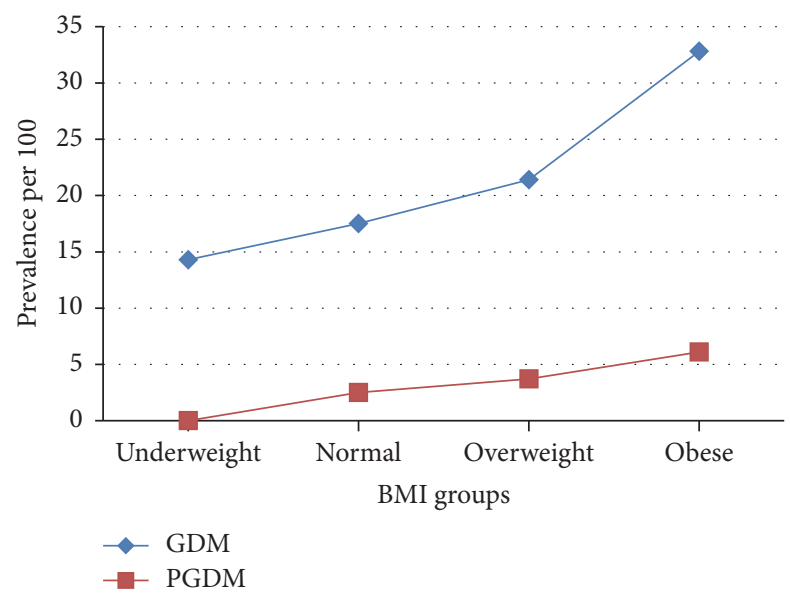

Figure 2: Prevalence of gestational diabetes and pregestational diabetes and body mass index groups.

Some of the recognized risk factors for the development of GDM and pre-GDM are well documented in this study, including increase in maternal age and obesity.

The association between advance age and development of GDM and pre-GDM is well established [20]. Our results showed increase in the prevalence of GDM and pre-GDM as the maternal age advances (Figure 1). This finding is consistent with previous studies from Saudi Arabia and other parts of the world for diabetes in pregnant and in nonpregnant subjects $[6,7,21]$. The slight drop in the prevalence of GDM at maternal age of 45 years is explained by the small number of pregnancies at this category of age and the sharp increase in the prevalence of pre-GDM to reach the national prevalence of $25 \%$ [18] (Figure 1).

Obesity is a risk factor for many maternal and perinatal adverse outcomes, including increased Cesarean section delivery, hypertensive disorders in pregnancy, macrosomia, and perinatal mortality $[22,23]$. In addition, obesity is associated with the development of T2DM and GDM due to the increased peripheral resistance to insulin [24].

In this study, the burden of overweight and obesity is very high in the whole cohort and especially among diabetic women. While as much as $65 \%$ of the nondiabetic women were either obese or overweight, the corresponding proportions of women with diabetes were 78 and $82 \%$ for GDM and pre-GDM, respectively. Furthermore, the prevalence of diabetes in the cohort increased with increase in BMI (Figure 2).

However, when we controlled for obesity as a covariant for adverse maternal and neonatal outcomes, pre-GDM continued to be a risk factor for all adverse outcomes except for shoulder dystocia, while the effect of GDM was attenuated to become a risk for no complication other than macrosomia (Table 3).

Few published studies compared the effects of GDM to those of pre-GDM $[25,26]$. Our results are consistent with the previous report which demonstrates that pre-GDM confers higher risk for adverse pregnancy outcomes including nearly fourfold increase in the risk of stillbirth and fetal distress and more than twofold increase in the risk of preterm birth and admission to NICU (Table 3). This can be explained by the longer exposure of the fetus to more severe hyperglycemic environment than in the case of GDM. The linear relationship between the degree of hyperglycaemia and the development of certain maternal and neonatal complications was recently established by the HAPO study and similar reports [27, 28].

Although the frequency of structural congenital abnormalities detected by mid-trimester ultrasound scan was more in the pre-GDM group compared to the other groups (Table 2), we expected to find higher rate. That expectation is based on the known teratogenic effect of pre-GDM and the fact that nearly $50 \%$ of the women in this cohort were diagnosed as T2DM at the time of screening and had received no treatment early in pregnancy [29]. Nevertheless, this estimate is associated with uncertainties such as the unknown 
sensitivity of the mid-trimester ultrasound scan in any center in Saudi Arabia for the detection of structural abnormalities.

Unfortunately, it will be difficult to link congenital anomalies detected in the postnatal period to any maternal condition due to lack of national registry for congenital anomalies and the difficulty of following a cohort of children with the frequent change of address and healthcare provider.

Similar to most of the published studies, we found no differences in terms of the complications we investigated between women with T1DM and T2DM except for preterm delivery (Table 4) [30,31]. Contrary to our expectations, we found similar frequency of adverse outcome reported for women known to have T2DM and those diagnosed during the index pregnancy. This may be explained by the shorter duration of the T2DM prior to the index pregnancy for women who did not know they had the condition and the lack of preconception control for women known to have the condition.

\section{Implication to Practice}

Although our estimated risks for maternal, fetal, and neonatal complications of pre-GDM and GDM are similar to other studies $[21,23,25,26,32]$, the impact on the Saudi pregnant population is expected to be bigger due to the high burden of these conditions in the community, which calls for immediate, evidence-based measures including the following:

(1) Preconception care should be integrated in the healthcare of Saudi diabetic women considering the proven effects associated with such services in reducing all the complications of pre-GDM [9].

(2) Early screening during pregnancy, preferably early in the first trimester, for pre-GDM, is a justified strategy of care, especially when $50 \%$ of women with T2DM in this study were diagnosed during pregnancy.

(3) Establishing national program for screening adults, including women in reproductive age, for diabetes and prediabetic state is a prudent step towards controlling such an epidemic. To reduce the cost of such a program, selective screening policy based on atrisk population, for example, high BMI, should be adopted.

(4) As diabetes in pregnancy is a major public health problem, it is mandatory to establish national guidelines for the screening and management of GDM and pre-GDM, which will standardize care, improve outcomes $[8,9]$, and provide the opportunity for monitoring.

(5) Establishment of national registries for main adverse effects of diabetes in pregnancy such as for congenital abnormalities, perinatal mortality, and Caesarean section will facilitate monitoring of interventions and will enhance audit and research.

(6) Postpartum screening of women with history of GDM for hyperglycemia and T2DM provides an opportunity for reducing the prevalence of $\mathrm{T} 2 \mathrm{DM}$ and its complications.
(7) Effective strategies should be implemented to reduce weight gain and obesity during pregnancy and in the postpartum period $[33,34]$.

(8) Saudi women in the reproductive age group should receive health education about the serious adverse effects of diabetes and obesity on their reproductive life. Such health education can be integrated in school and university education as over $90 \%$ of the women are attending schools or universities.

\section{Implication to Research}

Further research should be directed to the investigation of the prevalence of T2DM and prediabetic state following gestational diabetes and to the effects of maternal hyperglycaemia during pregnancy on the infant and the future adult health considering the proven ill effects of these conditions on the future adult $[35,36]$. In addition, research should be directed towards effective interventions to reduce the burden of obesity during pregnancy and its adverse effects.

\section{Strength and Limitations of the Study}

Our study is the first prospective report on a large cohort of nearly 10,000 participants, recruited from three centers, for the investigation of GDM and pre-GDM in the Middle East. An important strength of the study is the inclusion of a nondiabetic group in the analysis and the comparison between T1DM and T2DM. In addition, we have minimized the possibility of misclassification through reclassification of participants into GDM, pre-GDM, or nondiabetic groups, according to the WHO guidelines of diabetes in pregnancy, irrespective of the ICD coding, which increased the reliability of our results. The study investigated the effect of diabetes on many important maternal and neonatal outcomes and considered known covariates in the analysis to estimate the true effect of diabetes on the mother and the infant.

We acknowledge the limitations of this study including the fact that more than 4800 women were excluded from the study because they were not screened for diabetes. In addition, the BMI was calculated from the self-reported prepregnancy weight, which might have underestimated the prevalence of obesity and overweight. However, no significant difference in the prevalence of obesity was found when interpregnancy weight was estimated in the original cohort [3].

\section{Conclusion}

The prevalence of GDM and pre-GDM in the Saudi pregnant population is among the highest in the world. The conditions are associated with high maternal morbidities and fetal and neonatal morbidities and mortalities. Immediate effective interventions are needed to reduce the burden of diabetes in pregnancy.

\section{Appendix}

See Table 5. 
TABLE 5: Comparison of the main demographic characteristics and determinants of GDM between women who had OGTT test results and those who did not.

\begin{tabular}{lcc}
\hline Characteristic & $\begin{array}{c}\text { Women with data available for glycemic } \\
\text { classification } \\
\text { Mean } \pm \text { SD }\end{array}$ & $\begin{array}{c}\text { Women with missing data for glycemic } \\
\text { classification } \\
\text { Mean } \pm \text { SD }\end{array}$ \\
\hline Mother's Age (years) & $30.2 \pm 5.9$ & $29.3 \pm 5.9$ \\
Number of pregnancies & $3.7 \pm 2.5$ & $3.4 \pm 2.4$ \\
Number of deliveries & $2.3 \pm 2.1$ & $2.2 \pm 2.1$ \\
Mother's weight on delivery $(\mathrm{kg})$ & $78.7 \pm 14.8$ & $77.9 \pm 14.6$ \\
Gestational age at delivery (weeks) & $38.6 \pm 2.2$ & $38.4 \pm 2.5$ \\
Pregnancy BMI $\left(\mathrm{kg} / \mathrm{m}^{2}\right)$ & $31.8 \pm 5.8$ & $31.4 \pm 5.6$ \\
Prepregnancy BMI $\left(\mathrm{kg} / \mathrm{m}^{2}\right)$ & $28.4 \pm 5.6$ & $27.8 \pm 5.5$ \\
\hline
\end{tabular}

\section{Competing Interests}

The authors declare that they have no competing interests.

\section{Authors' Contributions}

Hayfaa Wahabi, Amel Fayed, and Samia Esmaeil were responsible for study conception and design, analysis plan, and funding acquisition. Hayfaa Wahabi and Amel Fayed were responsible for study implementation. Hayfaa Wahabi drafted the manuscript except for Methods and Results which were drafted by Amel Fayed, Heba Mamdouh, and Reham Kotb. All authors read the final draft of the manuscript and approved it. Hayfaa Wahabi and Amel Fayed contributed equally to this work.

\section{Acknowledgments}

The authors extend their gratitude to King Saud University, Deanship of Scientific Research, Research Chairs, for funding this study.

\section{References}

[1] International Diabetes Federation, IDF Diabetes Atlas, vol. 6th, International Diabetes Federation, Brussels, Belgium, 2013.

[2] A. Majeed, A. A. El-Sayed, T. Khoja, R. Alshamsan, C. Millett, and S. Rawaf, "Diabetes in the Middle-East and North Africa: an update," Diabetes Research and Clinical Practice, vol. 103, no. 2, pp. 218-222, 2014.

[3] H. Wahabi, A. Fayed, S. Esmaeil et al., "Riyadh mother and baby multicenter cohort Study: the cohort profile," PLoS ONE, vol. 11, no. 3, Article ID e0150297, 2016.

[4] Y. Zhu and C. Zhang, "Prevalence of gestational diabetes and risk of progression to type 2 diabetes: a global perspective," Current Diabetes Reports, vol. 16, no. 1, article 7, 2016.

[5] L. Guariguata, U. Linnenkamp, J. Beagley, D. R. Whiting, and N. H. Cho, "Global estimates of the prevalence of hyperglycaemia in pregnancy," Diabetes Research and Clinical Practice, vol. 103, no. 2, pp. 176-185, 2014.

[6] H. A. Wahabi, S. A. Esmaeil, A. Fayed, G. Al-Shaikh, and R. A. Alzeidan, "Pre-existing diabetes mellitus and adverse pregnancy outcomes," BMC Research Notes, vol. 5, article no. 496, 2012.
[7] H. A. Wahabi, S. A. Esmaeil, A. Fayed, and R. A. Alzeidan, “Gestational diabetes mellitus: maternal and perinatal outcomes in King Khalid University Hospital, Saudi Arabia," Journal of the Egyptian Public Health Association, vol. 88, no. 2, pp. 104-108, 2013.

[8] V. H. González-Quintero, N. B. Istwan, D. J. Rhea et al., “The impact of glycemic control on neonatal outcome in singleton pregnancies complicated by gestational diabetes," Diabetes Care, vol. 30, no. 3, pp. 467-470, 2007.

[9] H. A. Wahabi, R. A. Alzeidan, G. A. Bawazeer, L. A. Alansari, and S. A. Esmaeil, "Preconception care for diabetic women for improving maternal and fetal outcomes: a systematic review and meta-analysis," BMC Pregnancy and Childbirth, vol. 10, article no. $63,2010$.

[10] C. A. Crowther, J. E. Hiller, J. R. Moss, A. J. McPhee, W. S. Jeffries, and J. S. Robinson, "Effect of treatment of gestational diabetes mellitus on pregnancy outcomes," New England Journal of Medicine, vol. 352, no. 24, pp. 2477-2486, 2005.

[11] Saudi Ministry of Health Statistics Book, 2012, http://www.moh .gov.sa/en/Ministry/Statistics/book/Documents/StatisticsBook-1434.pdf.

[12] World Health Organization, "Diagnostic criteria and classification of hyperglycaemia first detected in pregnancy," Diabetes Research and Clinical Practice, vol. 103, pp. 341-363, 2014.

[13] World Health Organization, Global Database on Body Mass Index: BMI Classification, 2015, http://apps.who.int/bmi/index .jsp? introPage $=$ intro_3.html.

[14] National High Blood Pressure Education Program Working Group on High Blood Pressure in Pregnancy, "Report of the national high blood pressure education program working group on high blood pressure in pregnancy," American Journal of Obstetrics and Gynecology, vol. 183, no. 1, pp. S1-S22, 2000.

[15] K. Al-Rubeaan, H. A. Al-Manaa, T. A. Khoja et al., "A community-based survey for different abnormal glucose metabolism among pregnant women in a random household study (SAUDI-DM)," BMJ Open, vol. 4, no. 8, Article ID e005906, 2014.

[16] D. A. Savitz, T. M. Janevic, S. M. Engel, J. S. Kaufman, and A. H. Herring, "Ethnicity and gestational diabetes in New York City, 1995-2003," BJOG: An International Journal of Obstetrics and Gynaecology, vol. 115, no. 8, pp. 969-978, 2008.

[17] K. J. Hunt, N. M. Marlow, M. Gebregziabher et al., "Impact of maternal diabetes on birthweight is greater in non-Hispanic blacks than in non-Hispanic whites," Diabetologia, vol. 55, no. 4, pp. 971-980, 2012. 
[18] K. Al-Rubeaan, H. A. Al-Manaa, T. A. Khoja et al., "Epidemiology of abnormal glucose metabolism in a country facing its epidemic: SAUDI-DM study," Journal of Diabetes, vol. 7, no. 5, pp. 622-632, 2015.

[19] A. Ben-Haroush, Y. Yogev, and M. Hod, "Epidemiology of gestational diabetes mellitus and its association with Type 2 diabetes," Diabetic Medicine, vol. 21, no. 2, pp. 103-113, 2004.

[20] K. F. McFarland and C. A. Case, "The relationship of maternal age on gestational diabetes," Diabetes Care, vol. 8, no. 6, pp. 598600, 1985.

[21] H. Wahabi, A. Fayed, and S. Esmaeil, "Maternal and perinatal outcomes of pregnancies complicated with pregestational and gestational diabetes mellitus in Saudi Arabia," Diabetes and Metabolism, vol. 5, article 399, 2014.

[22] J. Marchi, M. Berg, A. Dencker, E. K. Olander, and C. Begley, "Risks associated with obesity in pregnancy, for the mother and baby: a systematic review of reviews," Obesity Reviews, vol. 16, no. 8, pp. 621-638, 2015.

[23] J. G. Ray, M. J. Vermeulen, J. L. Shapiro, and A. B. Kenshole, "Maternal and neonatal outcomes in pregestational and gestational diabetes mellitus, and the influence of maternal obesity and weight gain: the DEPOSIT study," QJM, vol. 94, no. 7, pp. 347-356, 2001.

[24] C. Percheron, C. Colette, D. Mariano-Goulart et al., "Relationship between insulin sensitivity, obesity, body fat distribution and $\beta$-endorphinaemia in obese women," International Journal of Obesity and Related Metabolic Disorders, vol. 22, no. 2, pp. 143-148, 1998.

[25] A. K. Shefali, M. Kavitha, R. Deepa, and V. Mohan, "Pregnancy outcomes in pre-gestational and gestational diabetic women in comparison to non-diabetic women-A Prospective Study in Asian Indian Mothers (CURES-35)," Journal of Association of Physicians of India, vol. 54, pp. 613-618, 2006.

[26] A. Fong, A. Serra, T. Herrero, D. Pan, and D. Ogunyemi, "Pregestational versus gestational diabetes: a population based study on clinical and demographic differences," Journal of Diabetes and its Complications, vol. 28, no. 1, pp. 29-34, 2014.

[27] D. Farrar, M. Simmonds, M. Bryant et al., "Hyperglycaemia and risk of adverse perinatal outcomes: systematic review and metaanalysis," BMJ, vol. 354, Article ID i4694, 2016.

[28] B. E. Metzger, L. P. Lowe, A. R. Dyer et al., "Hyperglycemia and adverse pregnancy outcomes," The New England Journal of Medicine, vol. 358, pp. 1991-2002, 2008.

[29] E. Zhao, Y. Zhang, X. Zeng, and B. Liu, "Association between maternal diabetes mellitus and the risk of congenital malformations: a meta-analysis of cohort studies," Drug Discoveries \& Therapeutics, vol. 9, no. 4, pp. 274-281, 2015.

[30] M. Balsells, A. García-Patterson, I. Gich, and R. Corcoy, "Maternal and fetal outcome in women with type 2 versus type 1 diabetes mellitus: a systematic review and metaanalysis," Journal of Clinical Endocrinology and Metabolism, vol. 94, no. 11, pp. 4284-4291, 2009.

[31] H. R. Murphy, S. A. Steel, J. M. Roland et al., "Obstetric and perinatal outcomes in pregnancies complicated by Typel and Type2 diabetes: influences of glycaemic control, obesity and social disadvantage," Diabetic Medicine, vol. 28, no. 9, pp. 10601067, 2011.

[32] M. N. Barakat, R. M. Youssef, and J. A. Al-Lawati, "Pregnancy outcomes of diabetic women: Charting oman's progress towards the goals of the saint vincent declaration," Annals of Saudi Medicine, vol. 30, no. 4, pp. 265-270, 2010.
[33] S. Lim, S. O’Reilly, H. Behrens, T. Skinner, I. Ellis, and J. A. Dunbar, "Effective strategies for weight loss in post-partum women: a systematic review and meta-analysis," Obesity Reviews, vol. 16, no. 11, pp. 972-987, 2015.

[34] B. Muktabhant, T. A. Lawrie, P. Lumbiganon, and M. Laopaiboon, "Diet or exercise, or both, for preventing excessive weight gain in pregnancy," The Cochrane database of systematic reviews, no. 6, Article ID CD007145, 2015.

[35] L. Kelstrup, P. Damm, E. R. Mathiesen et al., "Insulin resistance and impaired pancreatic $\beta$-cell function in adult offspring of women with diabetes in pregnancy," Journal of Clinical Endocrinology and Metabolism, vol. 98, no. 9, pp. 3793-3801, 2013.

[36] T. D. Clausen, E. R. Mathiesen, T. Hansen et al., "Overweight and the metabolic syndrome in adult offspring of women with diet-treated gestational diabetes mellitus or type 1 diabetes," Journal of Clinical Endocrinology and Metabolism, vol. 94, no. 7, pp. 2464-2470, 2009. 


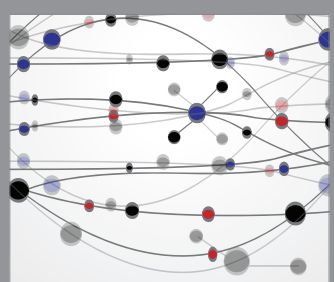

The Scientific World Journal
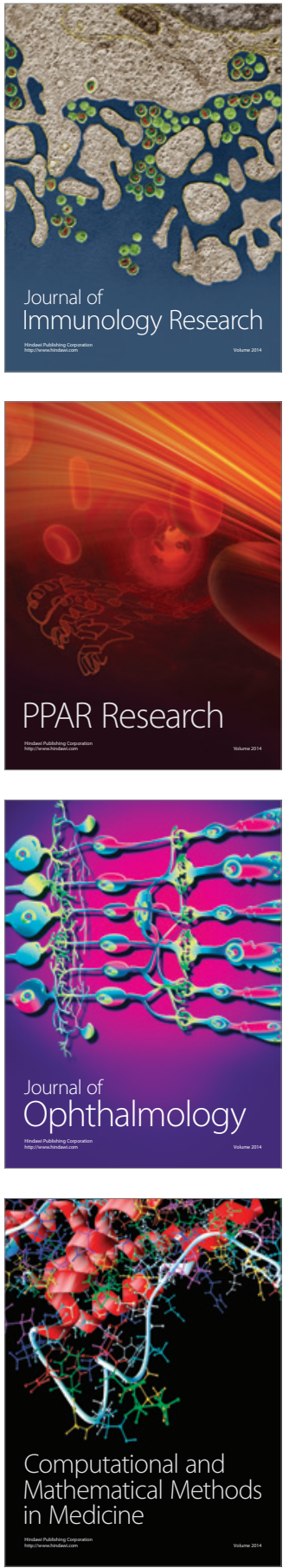

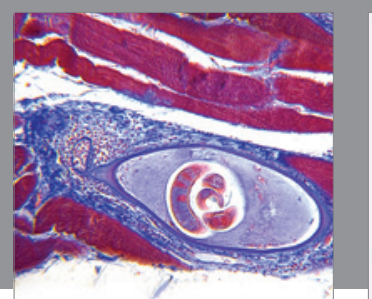

Gastroenterology Research and Practice
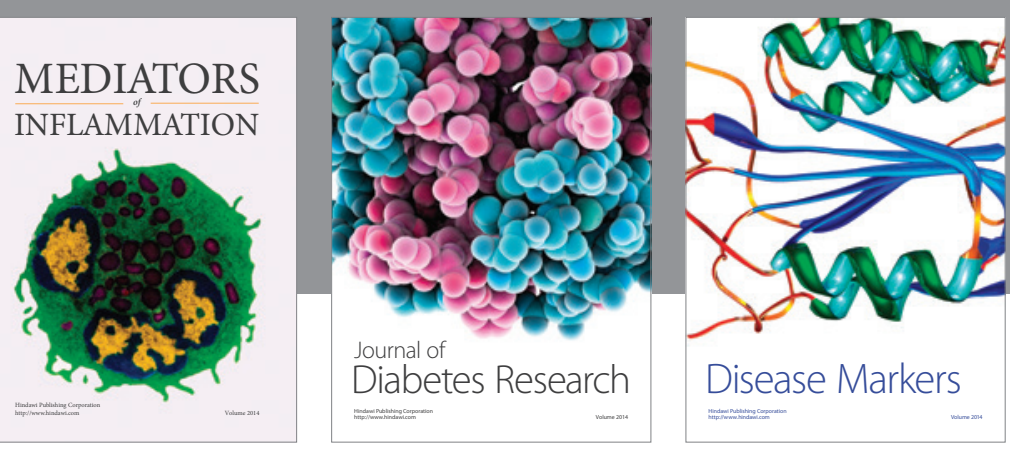

Disease Markers

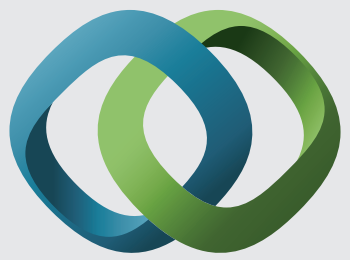

\section{Hindawi}

Submit your manuscripts at

https://www.hindawi.com
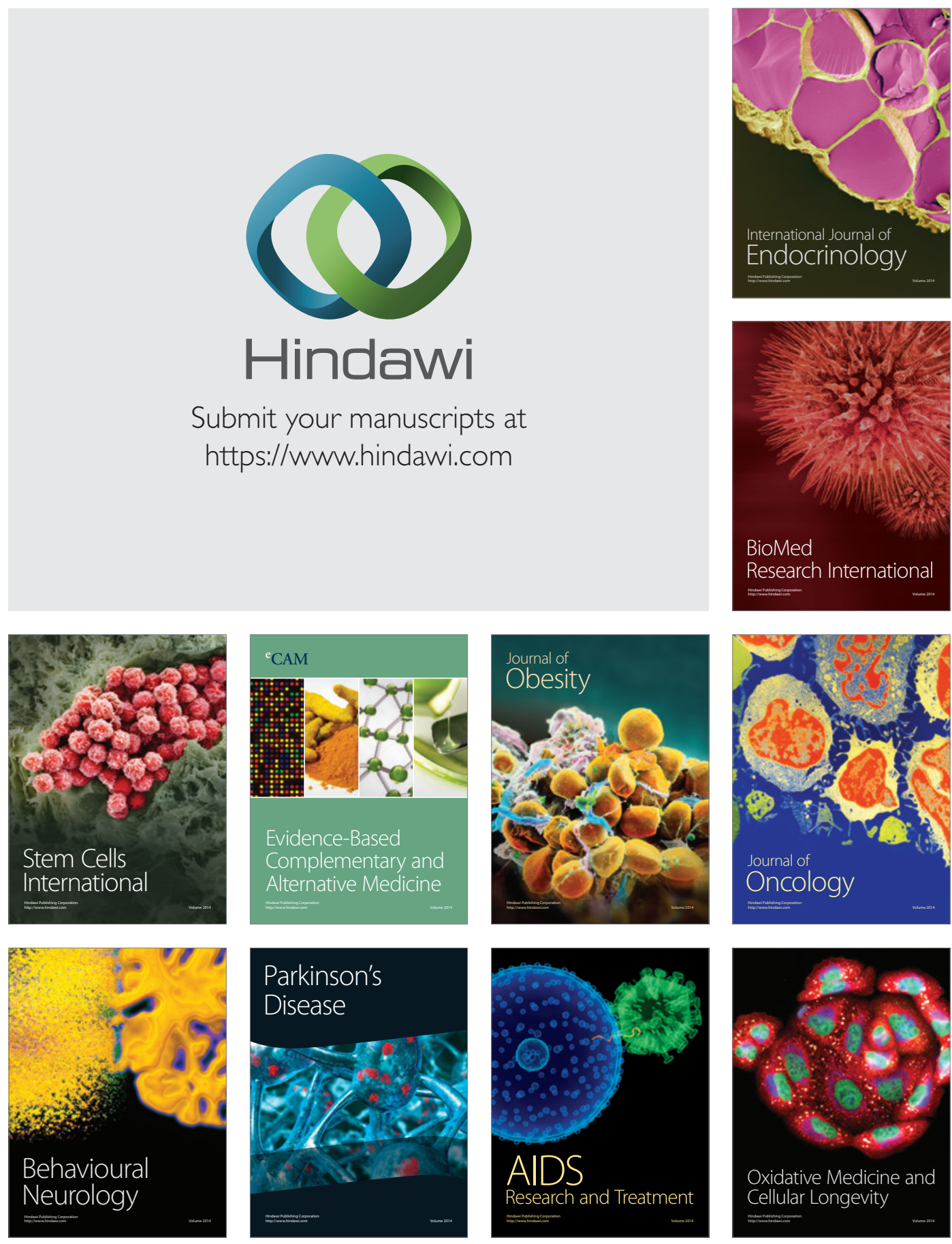